\title{
GERADOR DE HOMEÓSTATOS
}

Rui Torres*

Nuno Ferreira*

RESUMO: Motor textual combinatório em 10 versões, a partir dos Homeóstatos 1-9 e A de JoséAlberto Marques. Em cada uma das variações generativas (linhas, versos), pode ainda o leitor clicar para gerar indeterminados e variáveis homeóstatos. O Homeóstato $\mathrm{N}$ permite inserir texto livre, criando homeóstatos a partir do léxico seleccionado.

PALAVRAS-CHAVE: Homeóstatos. José-Alberto Marques. Poesia Experimental Portuguesa. Releitura.

O homeóstato, dispositivo de procura da entropia num dado sistema, quando aplicado por José-Alberto Marques ao texto, engendra uma simulação das condições de estabilidade (e legibilidade) sustentadas pelos seus mecanismos entrópicos. Na busca de um equilíbrio textual, na procura de um campo de leitura passível de gerar uma grande quantidade de informação estética, os poemas homeóstatos buscam a auto-organização e a independência, e fazem-no encontrando a temperatura própria do texto através de uma lógica de abertura e de indeterminação. Os versos do(s) poema(s) são repetidos de formas e em ocorrências variáveis, sujeitando, a cada repetição, uma nova camada de fragmentação textual, anulando determinadas palavras e letras e contruindo, desse modo, uma sucessão de variações homeostáticas que representam metonomicamente o todo do poema. Inspirados por este procedimento textual, concebemos e programámos os homeóstatos de J.-A.M. de modo a eles responderem, num primeiro nível, a um motor textual combinatório (10 versões programadas com o poemario.js). Num segundo nível, e 'em cima' de cada variação generativa (linha, verso), pode ainda o leitor clicar para gerar indeterminados e variáveis homeóstatos. O Homeóstato $\mathrm{N}$, por sua vez, permite ao leitor inserir o seu

\footnotetext{
*Universidade Fernando Pessoa, Porto, Portugal. E-mail: rtorres@ufp.edu.pt

** Principal Engineer na Critical Software e Tech lead em startup do mesmo grupo. E-mail: self@nunof.eu
} 
próprio texto poético para gerar homeóstatos com o léxico seleccionado.

Para aceder ao Gerador de Homeóstatos: <http://telepoesis.net/homeostatos>.

Fig. 1 - Imagem de Iteração (1 em n) realizada com o Gerador de Homeóstatos, a partir da recriação do Homeóstato 1, de José-Alberto Marques.

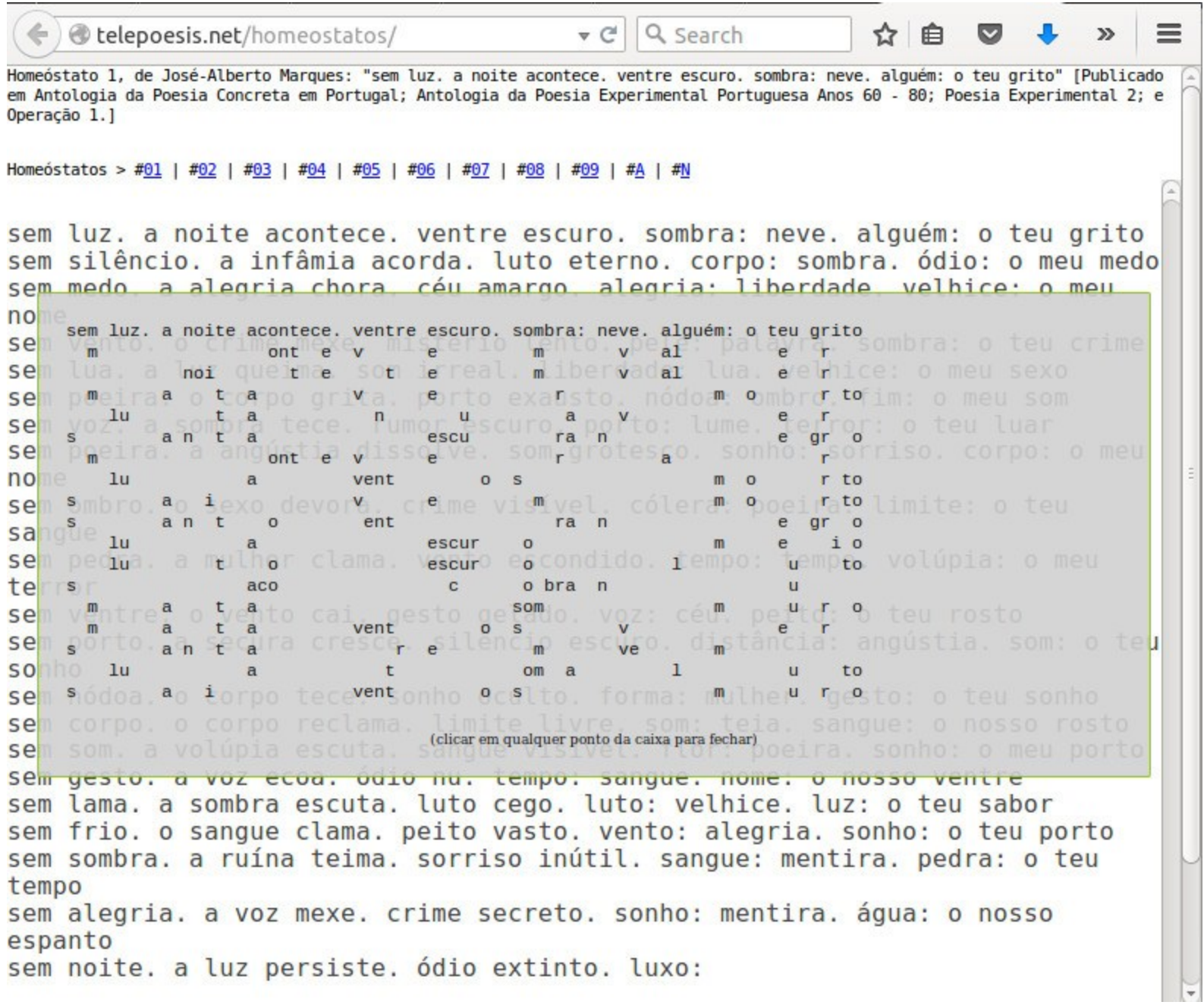

Texto Digital, Florianópolis, Santa Catarina, Brasil, v. 12, n. 1, p. 171-183, jan./jun. 2016. ISSNe: 1807-9288. 
Fig. 2 - Imagem de Iteração (1 em n) realizada com o Gerador de Homeóstatos, a partir da recriação do Homeóstato 2, de José-Alberto Marques.

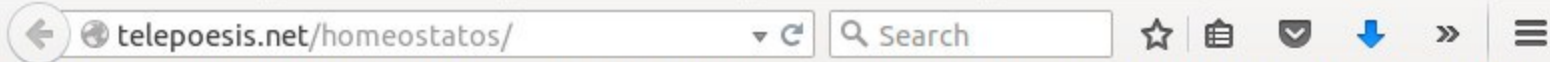

Homeóstato 2, de José-Alberto Marques: "vermelhos teus sonhos de lume: liberdade quente: ossos" [Publicado em Antologia da Poesia Concreta em Portugal; e Operaçăo 1.]

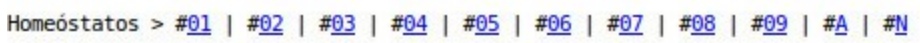

vermelhos teus sonhos de lume: liberdade quente: ossos

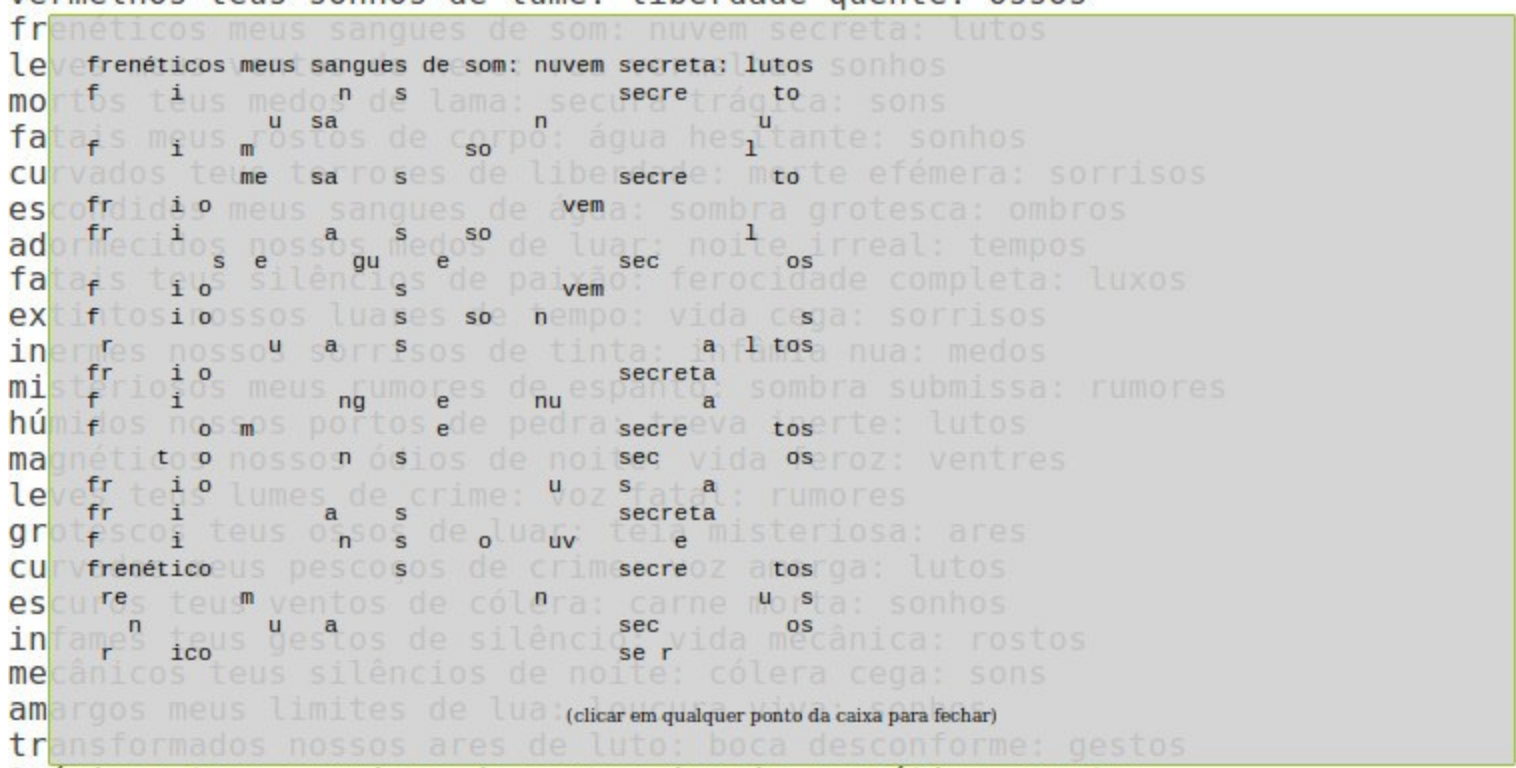

trágicos teus sorrisos de carne: inveja magnética: ventos

gelados meus sons de rosto: desgraça curvada: ossos

curvados teus ventos de corpo: secura escura: ventres

antigos nossos nomes de rosto: teia intensa: sorrisos 
Fig. 3 - Imagem de Iteração (1 em n) realizada com o Gerador de Homeóstatos, a partir da recriação do Homeóstato 3, de José-Alberto Marques.

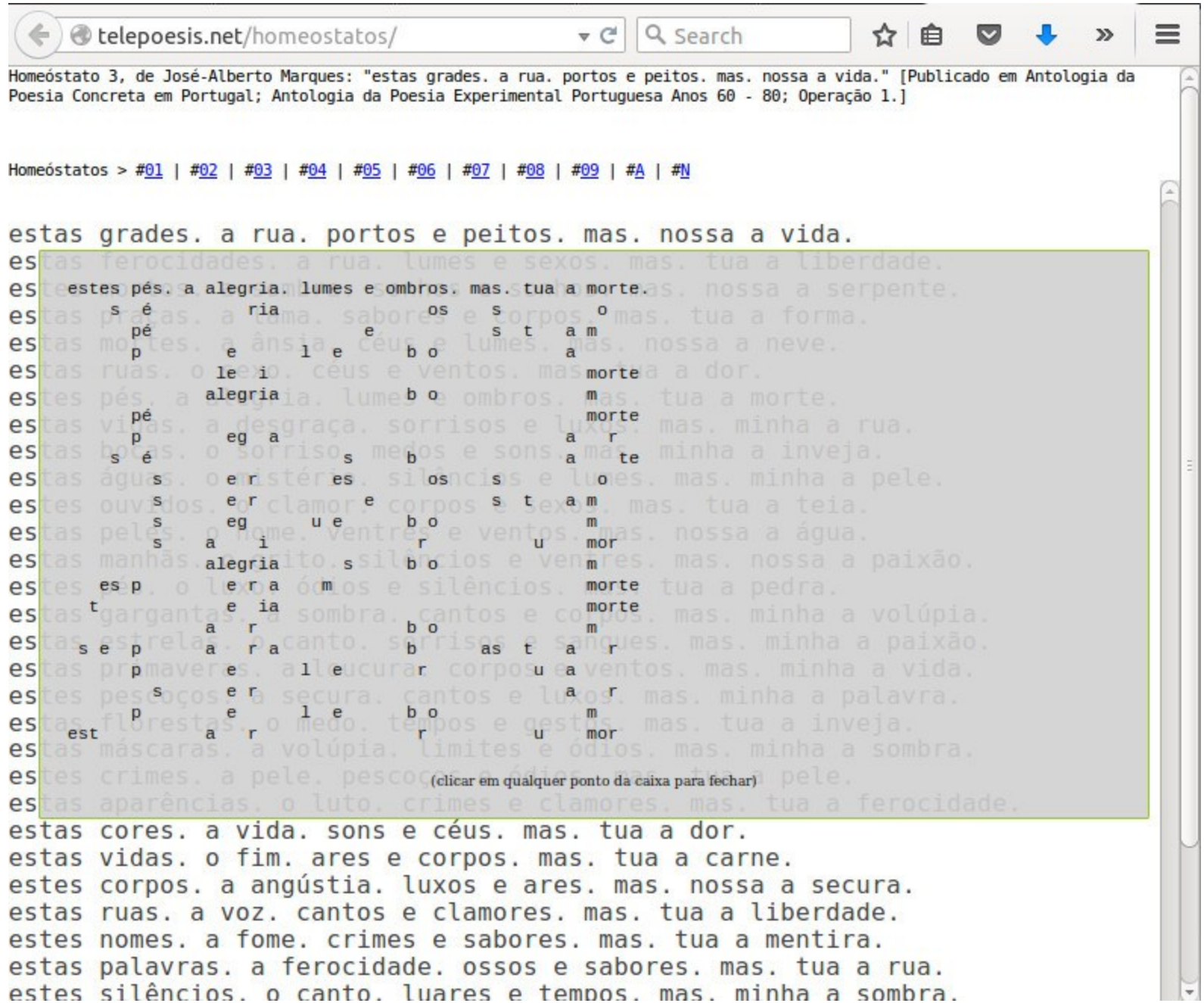


Fig. 4 - Imagem de Iteração (1 em n) realizada com o Gerador de Homeóstatos, a partir da recriação do Homeóstato 4, de José-Alberto Marques.

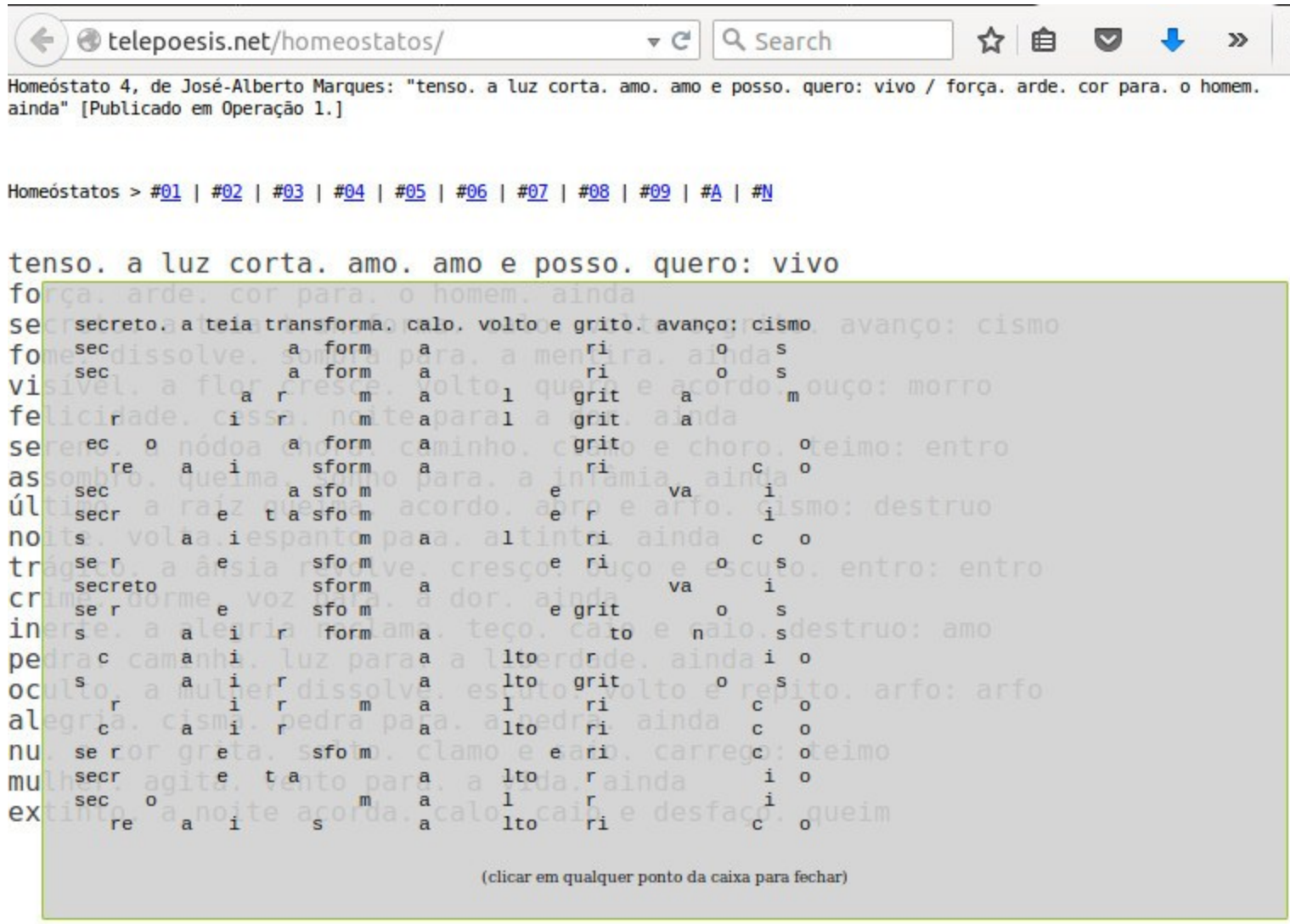


Fig. 5 - Imagem de Iteração (1 em n) realizada com o Gerador de Homeóstatos, a partir da recriação do Homeóstato 5, de José-Alberto Marques.

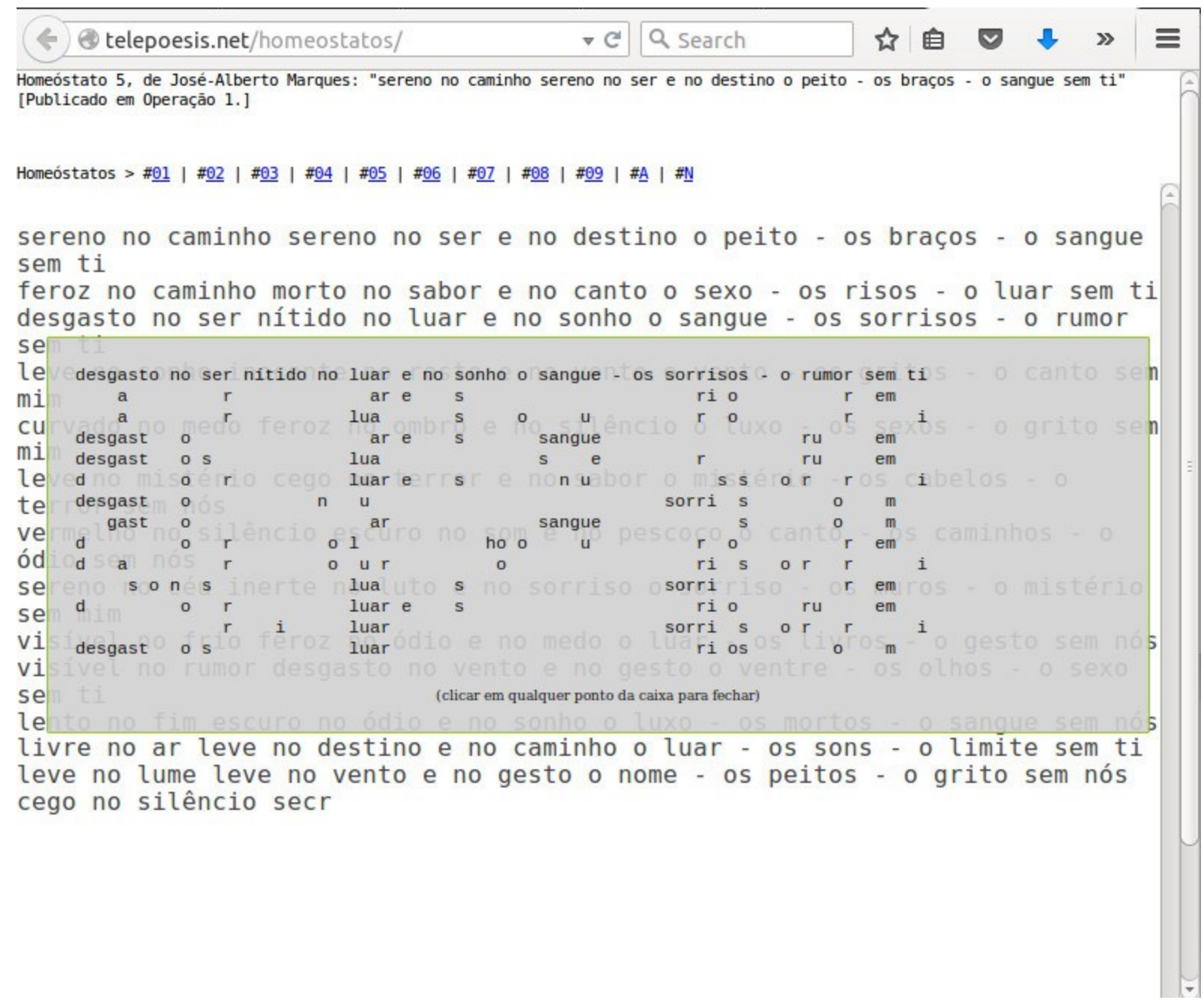

Texto Digital, Florianópolis, Santa Catarina, Brasil, v. 12, n. 1, p. 171-183, jan./jun. 2016. ISSNe: 1807-9288. 
Fig. 6 - Imagem de Iteração (1 em n) realizada com o Gerador de Homeóstatos, a partir da recriação do Homeóstato 6, de José-Alberto Marques.

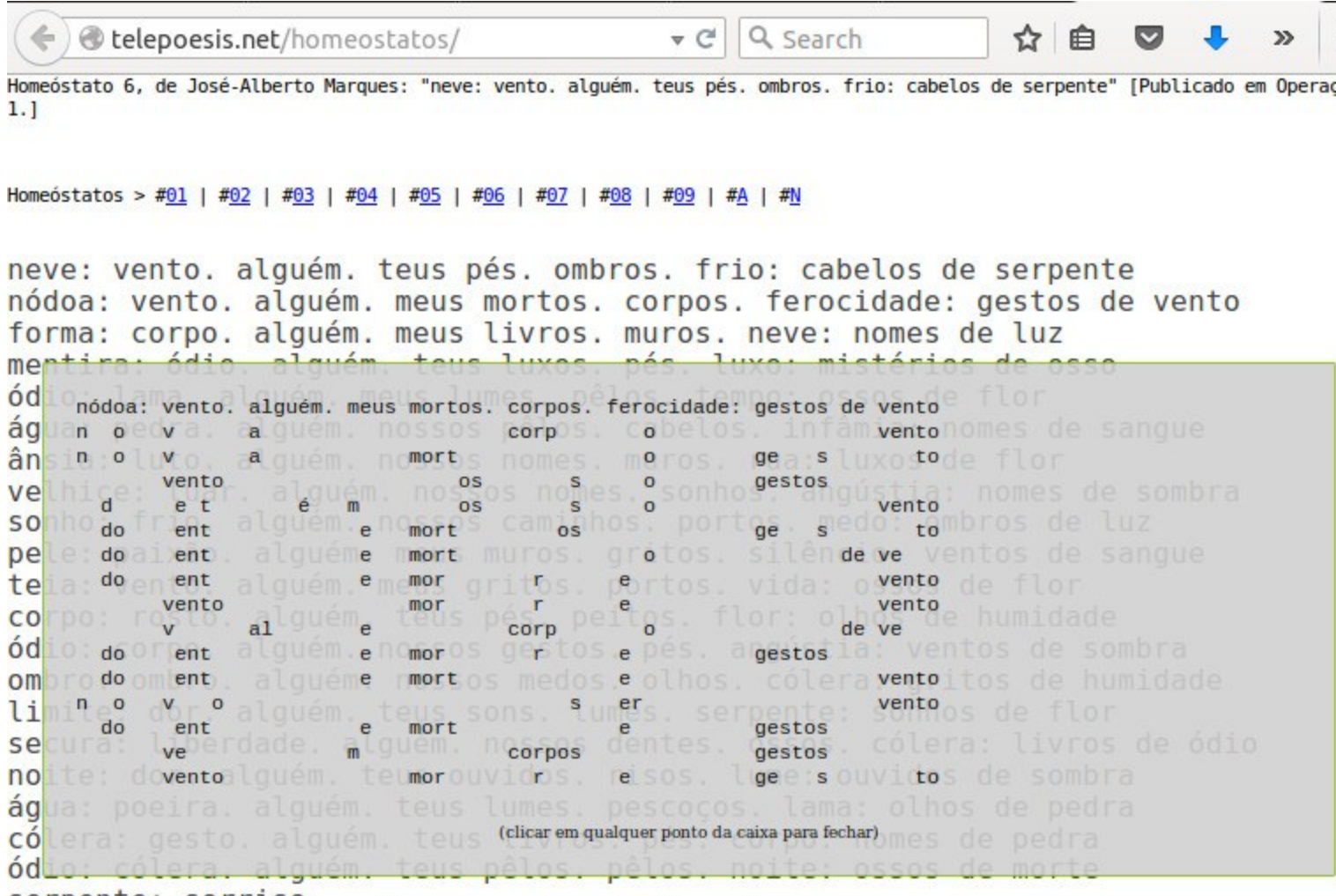

serpente: sorriso

Texto Digital, Florianópolis, Santa Catarina, Brasil, v. 12, n. 1, p. 171-183, jan./jun. 2016. ISSNe: 1807-9288. 
Fig. 7 - Imagem de Iteração (1 em n) realizada com o Gerador de Homeóstatos, a partir da recriação do Homeóstato 7, de José-Alberto Marques.

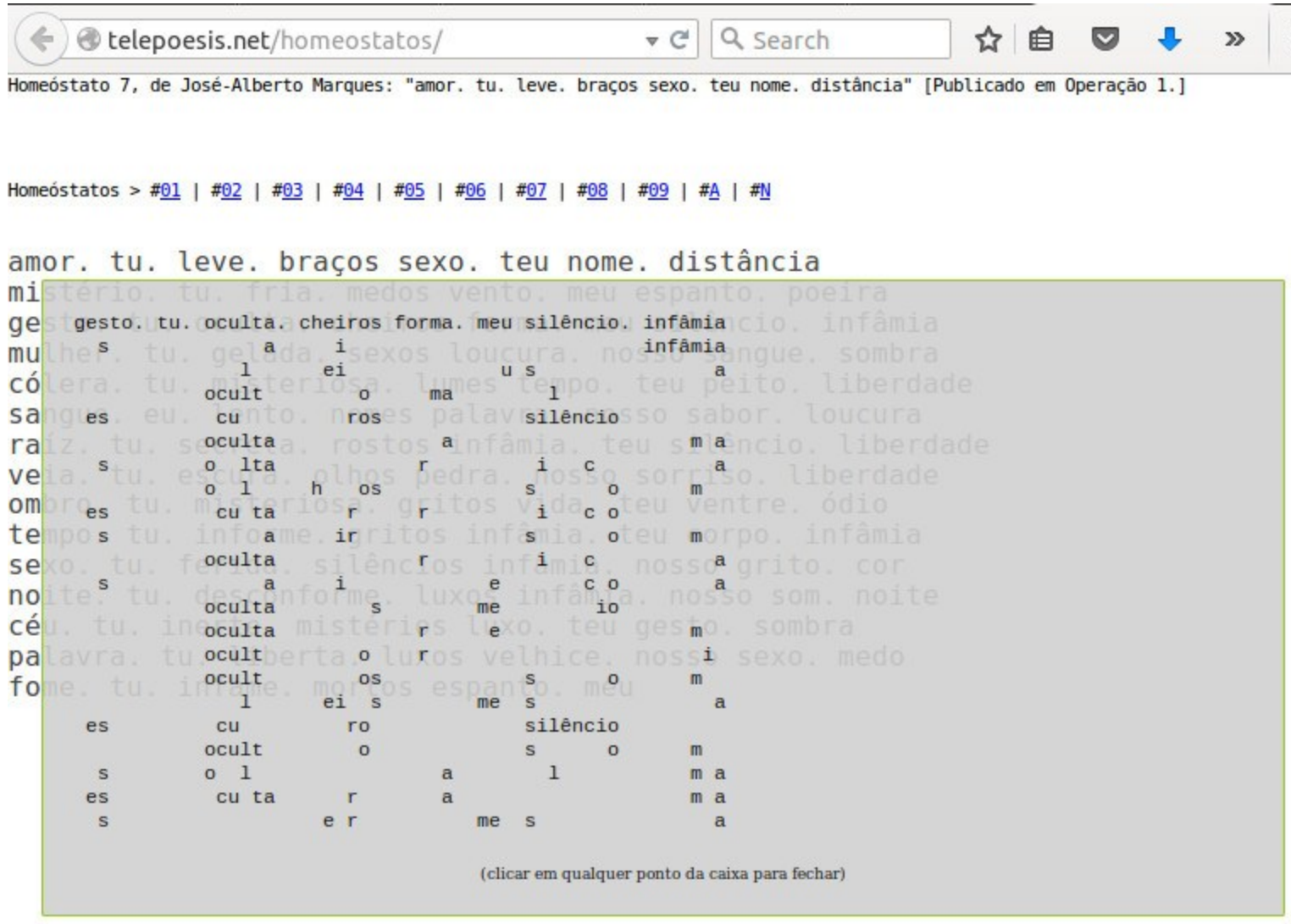


Fig. 8 - Imagem de Iteração (1 em n) realizada com o Gerador de Homeóstatos, a partir da recriação do Homeóstato 8, de José-Alberto Marques.

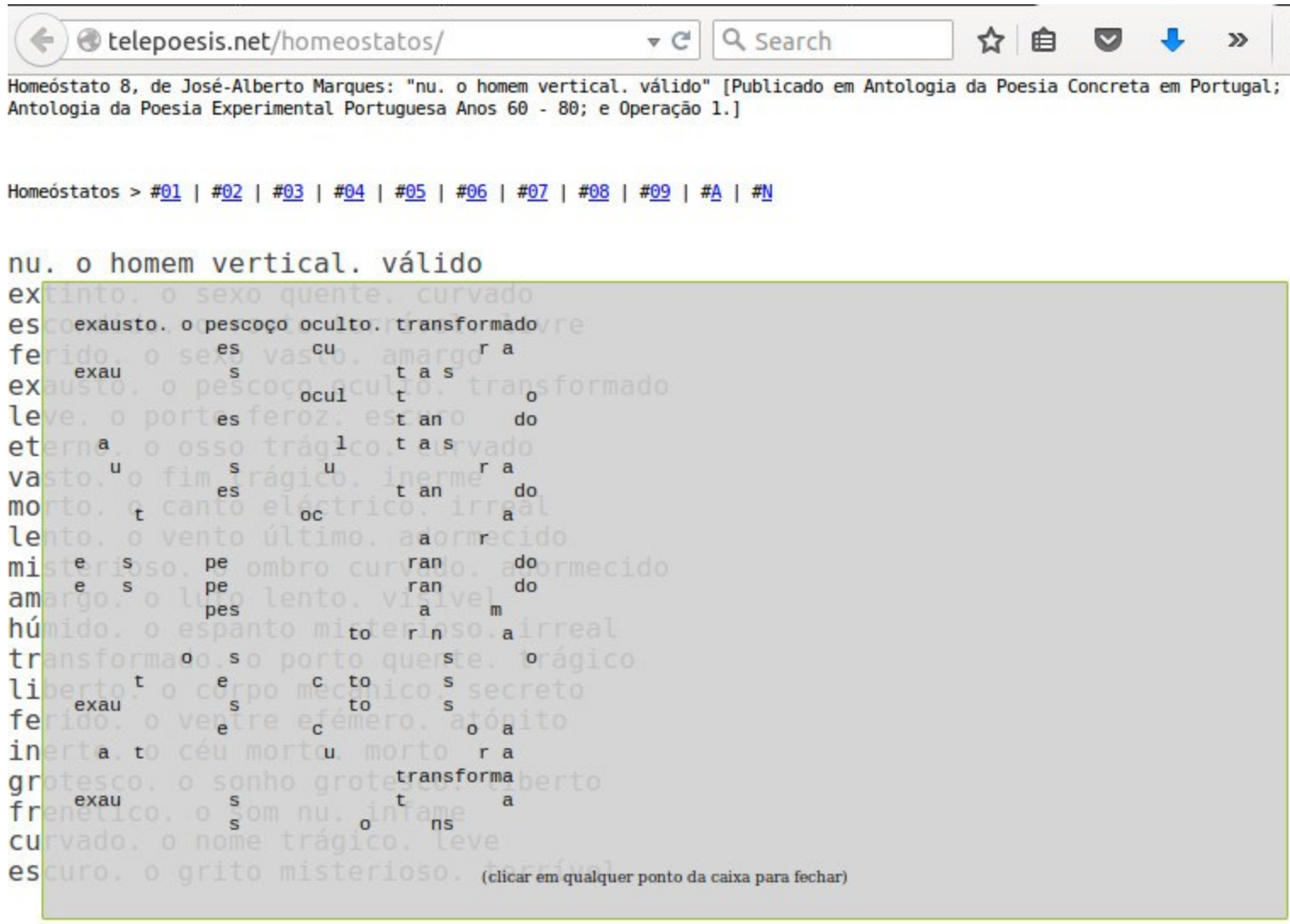


Fig. 9 - Imagem de Iteração (1 em n) realizada com o Gerador de Homeóstatos, a partir da recriação do Homeóstato 9, de José-Alberto Marques.

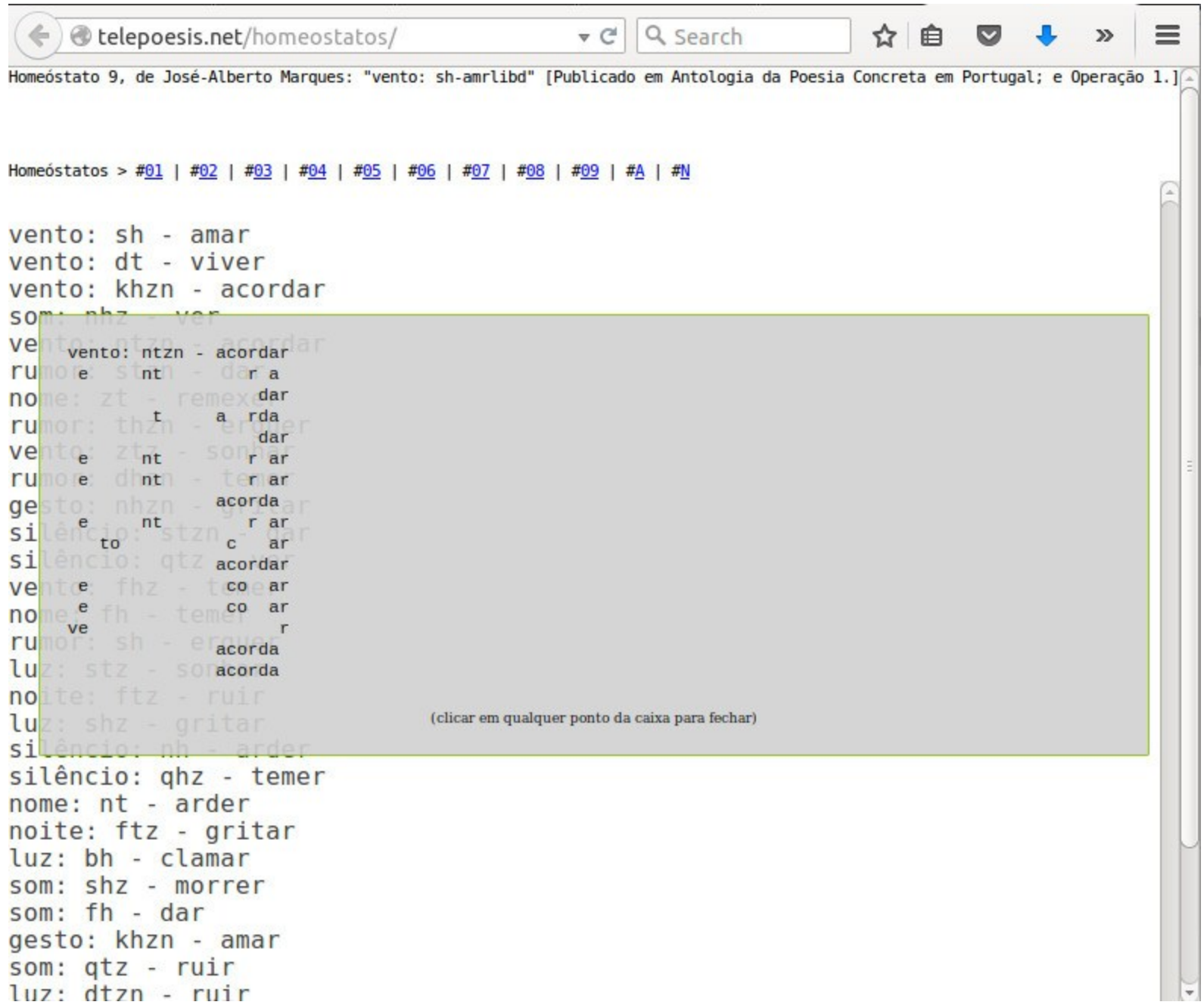


Fig. 10 - Imagem de Iteração (1 em $n$ ) realizada com o Gerador de Homeóstatos, a partir da recriação do Homeóstato A, de José-Alberto Marques.

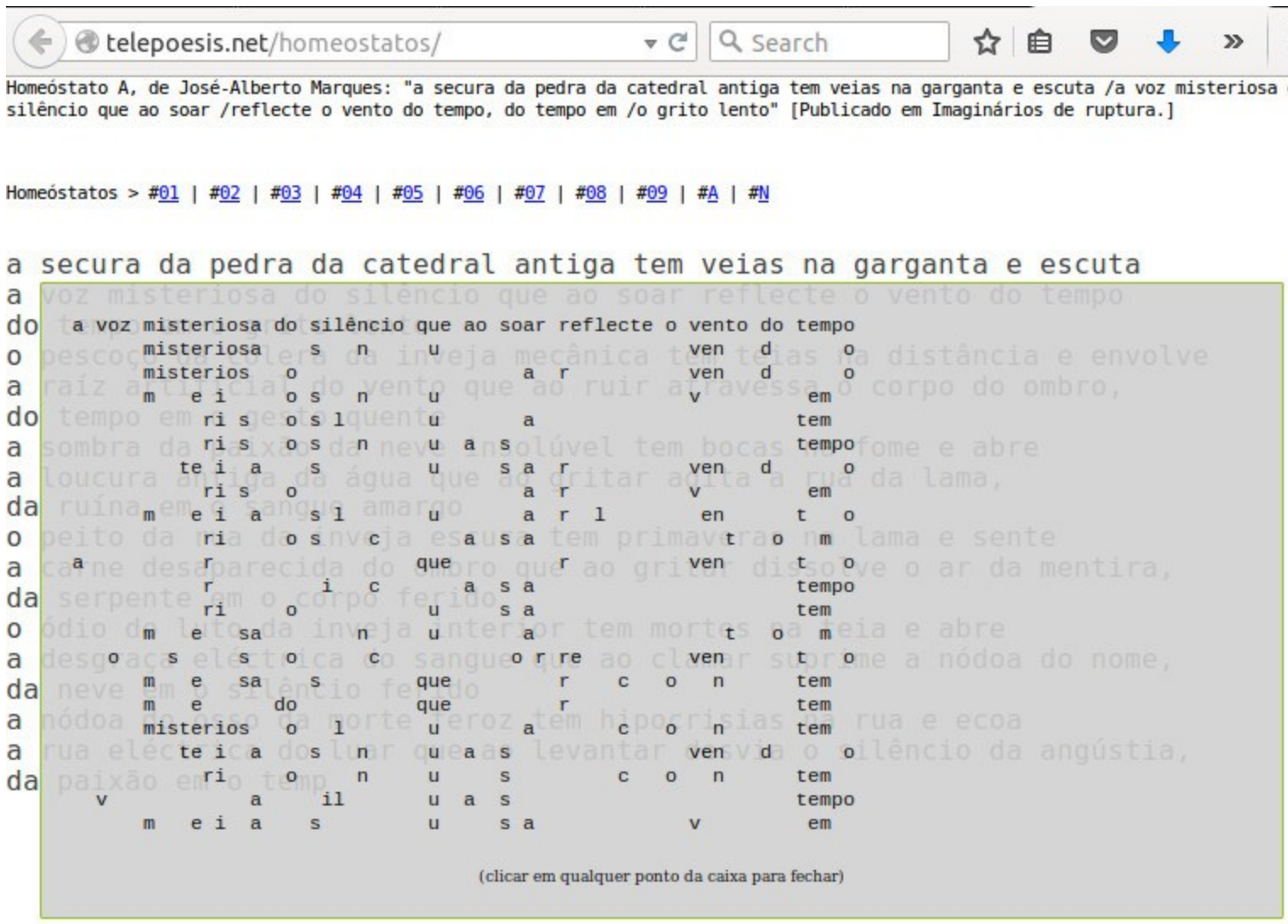


Fig. 11 - Imagem de Iteração (1 em n) realizada com o Gerador de Homeóstatos, a partir do Homeóstato $\mathrm{N}$.

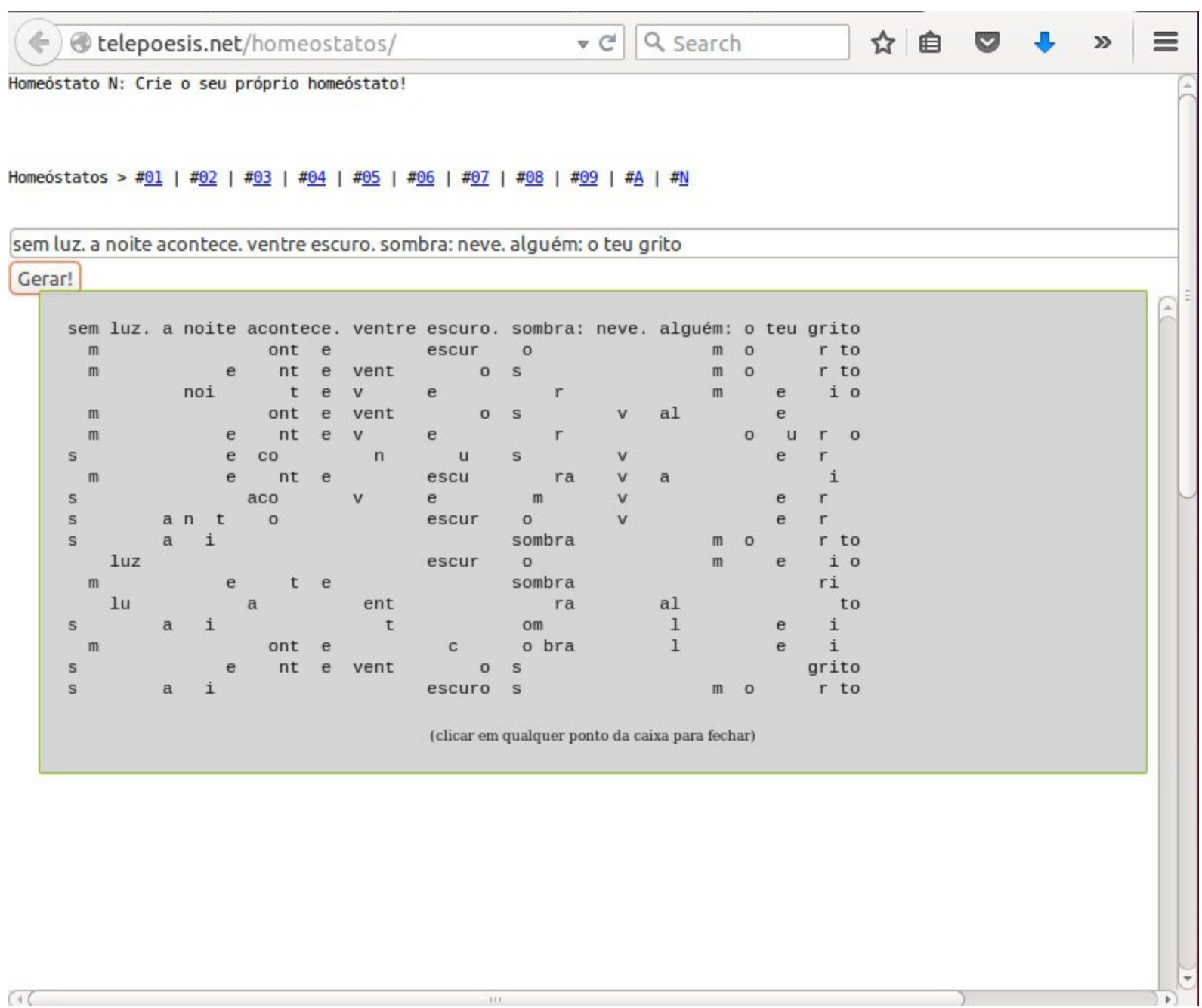


Fig. 12 - Imagem de Iteração (2 em n) realizada com o Gerador de Homeóstatos, a partir do Homeóstato N.

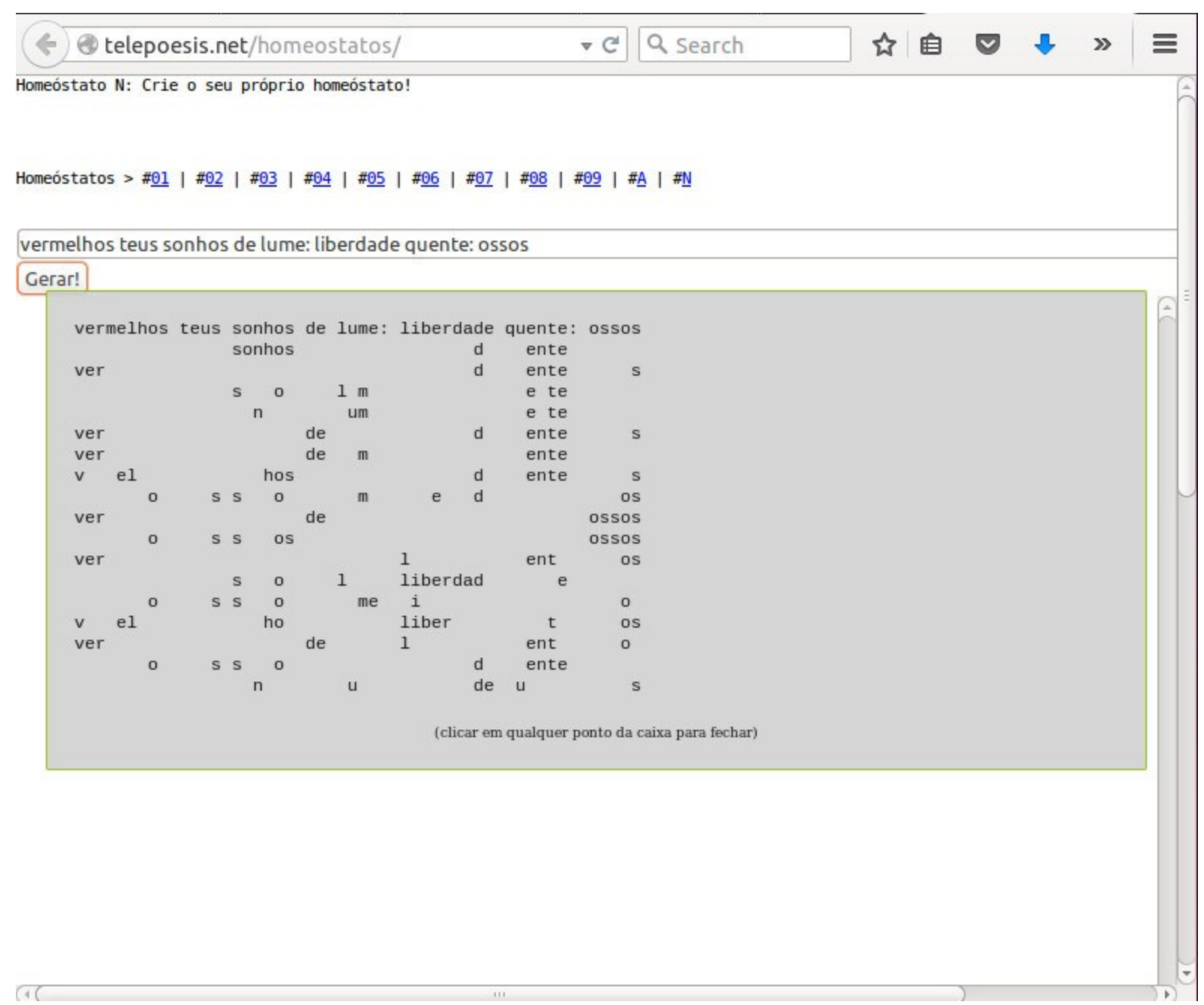

\section{GENERATOR OF HOMEOSTATS}

ABSTRACT: Combinatorial and textual engine in 10 versions, dialoguing with Homeóstatos 1-9 and $A$, by José-Alberto Marques. In each of the generative variations (rows, lines), the reader can click to generate homeóstatos indeterminate and variable. The homeostat $\mathrm{N}$ allows the reader to generate from her own text.

KEYWORDS: Homeóstatos. José-Alberto Marques. Portuguese Experimental Poetry. Cyberliterature. 